\title{
Application of Neurochemical Markers for Assessing Health Effects after Developmental Methylmercury and PCB Coexposure
}

\author{
E. Roda, ${ }^{1}$ L. Manzo, ${ }^{1,2}$ and T. Coccini ${ }^{1}$ \\ ${ }^{1}$ Laboratory of Clinical Toxicology, Salvatore Maugeri Foundation IRCCS, Institute of Pavia, 27100 Pavia, Italy \\ ${ }^{2}$ Department of Internal Medicine and Therapeutics, Division of Toxicology, University of Pavia, 27100 Pavia, Italy \\ Correspondence should be addressed to E. Roda, elisa.roda@fsm.it
}

Received 19 July 2011; Accepted 21 October 2011

Academic Editor: Yasir Hasan Siddique

Copyright $(2012$ E. Roda et al. This is an open access article distributed under the Creative Commons Attribution License, which permits unrestricted use, distribution, and reproduction in any medium, provided the original work is properly cited.

\begin{abstract}
Cholinergic muscarinic receptors (MRs) and monoamine oxidase activity (MAO-B), expressed both in brain and blood cells, were investigated in animals and exposed subjects to assess (i) MeHg (0.5-1 mg/kg/day GD7-PD7) and/or PCB153 (20 mg/kg/day GD10-GD16) effects on cerebellar MAO-B and MRs, and lymphocyte MRs, in dams and offspring 21 days postpartum; (ii) MAO$\mathrm{B}$ in platelets and MRs in lymphocytes of a Faroese 7-year-old children cohort, prenatally exposed to MeHg/PCBs. Animal Data. MAO-B was altered in male cerebellum by MeHg, PCB153, and their combination (35\%, 45\%, and 25\% decrease, resp.). Cerebellar MRs were enhanced by MeHg alone in dams (87\%) and male pups (27\%). PCB153 alone and in mixture did not modify cerebellar MRs. Similarly to brain, lymphocyte MRs were enhanced in both dams and offspring by MeHg alone. All changes were caused by $1 \mathrm{MeHg} \mathrm{mg} / \mathrm{kg} /$ day, the lower dose was ineffective. Human Data. Both biomarkers showed homogeneous distributions within the cohort (MRs, range $0.1-36.78 \mathrm{fmol} / \mathrm{million}$ cells; MAO-B, $0.95-14.95 \mathrm{nmol} / \mathrm{mg}$ protein $/ \mathrm{h}$ ). No correlation was found between the two biomarkers and neurotoxicant concentrations in blood (pre- and postnatally).
\end{abstract}

\section{Introduction}

In the last few decades, the continuous exposure of humans to complex mixture of contaminating substances in food is an issue that has been giving increasing cause for concern. Clinical and experimental research has demonstrated the high vulnerability of the developing nervous system to toxic insults, leading to permanent alteration of brain functions and pathologies later in life $[1,2]$. Among the neurodevelopmental toxicants that received attention in this regard, methylmercury $(\mathrm{MeHg})$ and polychlorinated biphenyls (PCBs) represent a great public health concern, because low-level chronic exposure can occur at various world sites through the consumption of contaminated fish, seafood, and marine mammals meat.

The neurotoxic hazard posed by $\mathrm{MeHg}$ and PCBs as well as the unique susceptibility of the developing brain are well documented $[3,4]$ but no definitive conclusion has yet been reached about the dose-response relationship [5-7], that remain unclear, particularly in relation to concomitant exposures.
Noteworthy, several epidemiologic studies on neurobehavioural endpoints in fish-eating populations at various world sites, including the Faroe Islands [8], the Madeira Island [9], the Brazilian Amazon basin, and more recent investigations on north-american Cree Indian infants, New-Yorkers and Bostonian inhabitants, and European fish consumers, demonstrated mercury-related neuropsychological or neurophysiological adverse effects in the offspring, in the domains of language, attention and memory, as well as visuospatial and motor functions $[6,10,11]$.

These effects may have been augmented by concomitant exposure to PCBs, which may affect similar neurobehavioural endpoints $[12,13]$.

Children exposed to PCBs and related chemicals in utero or through breastfeeding have an increased incidence of headaches, cognitive deficits, and significantly delayed psychomotor development [14]. In experimental animal models, a number of long-lasting impairments, for example, learning, behavioural, and neurochemical alterations have been described following maternal exposure to PCBs [1519]. 
Because human populations are often exposed to mixtures, as also for MeHg and PCBs in food, raising questions about possible additive, synergistic, or antagonistic effects of the components [20], the potential of these pollutants to interact, and the valuation of their joint effects should be thoroughly investigated, even though it is extremely difficult in epidemiological studies.

To gain this goal, studies investigating biochemical parameters in easily accessible non-neural tissues, which are similar to those targeted by chemicals in the brain (see [21]), may represent a successful approach to developing markers of neurotoxicity, which could be useful in exposed people $[22,23]$. In this respect, candidate non-invasive surrogate markers include neurotransmitter receptors, enzymes, and cell signalling components, which are measurable in blood, plasma, lymphocytes, and/or platelets and can be affected by neurotoxicants in these peripheral tissues with changes mirroring those occurring in the brain [21,24-27].

Examples of these peripheral markers include the cholinergic muscarinic receptors (MRs) in lymphocytes and the enzyme activity of monoamine oxidase- $\mathrm{B}(\mathrm{MAO}-\mathrm{B})$ in platelets [27-29].

The cholinergic system, essential for normal brain development [30], is a sensitive target for $\mathrm{MeHg}$ neurotoxicity $[31,32]$. Both in vitro and in vivo evidences indicate that the cholinergic muscarinic system can be affected by $\mathrm{MeHg}$ $[25,33-40]$, as well as by PCBs during development [41-43]. Notably, coexposure to $\mathrm{MeHg}$ and either PCB153 or PCB126 had the same effect on the cerebral MRs as exposure to each compound alone [28]. It has to be considered that changes in levels and activity of MRs have been implicated in the pathophysiology of many major diseases of the CNS [44-48].

Noticeably, in mammalian species, most of the cholinergic components found in the CNS, including MRs, are also expressed in non-neuronal tissues including lymphocytes isolated from peripheral blood, thymus, lymph nodes, and spleen [49]. Accordingly, some neurotransmission parameters measured in rats, including lymphocytes MRs, after the exposure to neurotoxicants and muscarinic drugs [35, 43, 50-52], have been shown to mirror equivalent changes of these biochemical end-points in the CNS, thus providing accessible measures of the same neurochemical endpoints express in the CNS.

Both MeHg and PCBs may also affect the central monoaminergic system as well. In fact, altered dopaminergic neurotransmission has been observed following perinatal exposure to $\mathrm{MeHg}(0.5 \mathrm{mg} / \mathrm{kg} /$ day, GD7-PND7) in rats [53, 54]; moreover, $\mathrm{MeHg}$ can stimulate the spontaneous release of monoamines from different experimental CNS tissue preparations $[55,56]$. The most consistent neurochemical effects of noncoplanar PCBs have been found to be a reduction in dopamine (DA) concentrations besides an increase in DA concentration both in cells and striatal tissue cultures [57-59] as well as in laboratory animals brains after developmental or adult exposure (for a review, [18]), with an exacerbation of the effects of the two contaminants acting synergistically when coadministrated [58]. On the other hand, in a recent in vivo study, we demonstrated that perinatal exposure to $\mathrm{MeHg}(0.5 \mathrm{mg} / \mathrm{kg} /$ day $)$ and/or PCB153
( $5 \mathrm{mg} / \mathrm{kg} /$ day) given orally to rat dams, affected D1 and D2 receptors in a gender-, time-, and brain area-dependent fashion, without additive effects of the two chemical compounds when administrated in mixture [60].

Noticeably, both $\mathrm{MeHg}$ and $\mathrm{PCBs}$ may alter the activity of the enzyme monoamine oxidase (MAO), which play an important role in the degradation of monoamine neurotransmitters as well as in the neurochemical regulation of behaviour. Experimental evidences in laboratory animals showed that (i) MeHg inhibited MAO activity both in vivo and in vitro $[61,62]$ and (ii) prenatal exposure to PCB77 depressed postnatal development of MAO activity in whole rat brain [63]. Recently, perinatal exposure to $\mathrm{MeHg}$ or PCB153 in rats was shown to induce regional alterations of the central dopaminergic and serotonergic systems at weaning, but the combined treatment with both these toxicants does not exacerbate the neurochemical effects of the compounds alone [28].

In humans, the MAO-B isoenzyme is the predominant form in the brain and the sole type present in platelets. The amino acid sequences of MAO-B in both platelets and brain are identical [64], and the biochemical and pharmacological characteristics of the enzyme are also similar in the two tissues [65]. In this respect, platelet MAO has been widely used as a model of central neuronal function and a surrogate marker to investigate neurological and psychiatric disorders [66-70].

With the ultimate goal to identify potential biomarkers of CNS effects, which can be applied as accessible tools to use in environmental medicine for assessing and monitoring specific exposure scenarios, a series of in vivo experimental studies have been planned in our laboratory. Specifically, in the attempt to advance knowledge on these biomarkers, a first-step study has been performed in order to evaluate (i) brain and lymphocytes MRs and (ii) cerebral MAO-B activity, investigated in both dams and offspring at weaning, after perinatal exposure to $\mathrm{MeHg}(0.5 \mathrm{mg} / \mathrm{kg} /$ day or $1 \mathrm{mg} / \mathrm{kg} / \mathrm{day}$, from gestational day (GD)7 to postnatal day (PD)7, and PCBs $(20 \mathrm{mg} / \mathrm{kg} /$ day from GD10 to GD16) alone and in combination. Then, in a second step, MRs in lymphocytes (1MRs) and MAO-B in platelets (p-MAO-B) have been applied in a selected human population, with the aim at supporting (i) the predictive value of these biomarkers and (ii) the relevance of a translational approach in environmental medicine.

\section{Experimental Protocols}

2.1. Animal Studies. All experimental procedures involving animals were performed in compliance with the European Council Directive 86/609/EEC on the care and use of laboratory animals. Adult Sprague-Dawley rats (12 females and 4 males, 12 weeks old for each set of experiment) were purchased from Charles River Italia (Calco, Italy) at least 2 weeks before mating and allowed to acclimatize for 3 weeks. Throughout the experiment, animals were kept in an artificial $12 \mathrm{~h}$ light $: 12 \mathrm{~h}$ dark cycle with humidity at $50 \pm 10 \%$. Animals were provided rat chow (VRF1 diet) and tap water ad libitum. 
To mimic human developmental dietary exposure to this contaminant, rats were exposed to low-to-moderate doses of $\mathrm{MeHg}$ and PCB153 in utero, through maternal oral consumption.

The experimental regimen comprises 0.5 and $1 \mathrm{mg}$ $\mathrm{MeHg} / \mathrm{kg}$ (body weight) bw/day, administered to rat dams in the drinking water from gestational day (GD)7 to postnatal (PD)7, and/or PCB153 (20 mg/kg/day) dissolved in corn oil, administered to rats from GD10 to GD16.

The endpoints investigated in rats included total cholinergic MRs and MAO-B activity in cerebellum and total MRs in lymphocytes at weaning (i.e., PD21) both in dams and their offspring.

At the day of sacrifice, rat brains were rapidly dissected on ice to isolate cerebellum from dams and offspring and stored at $-80^{\circ} \mathrm{C}$ until the analyses were performed. Spleens were also collected.

2.2. Human Population. The Faroese birth cohort $(n=182)$ was established in 1994-1995 and consisted of singleton term births. The studies adhered to the Declaration of Helsinki and have been performed after approval of the Faroese ethical review committee. All subjects participating in the clinical studies have been included after parental written informed consent. Of the original 182 cohort members, 177 were eligible for participation in the 7-year examinations, and 166 agreed to participate (94\%). A total of 159 children ( 76 boys, 83 girls) completed their examinations at 7 years of age with a voluntary blood sample for the exposure analyses and for the determination of biochemical markers: MAO-B activity in platelet and MR binding in lymphocytes.

2.3. MR and MAO-B Determinations in Rat Cerebellum. (i) Total MRs in cerebellum were determined by saturation binding assays using the specific muscarinic antagonist $\left[{ }^{3} \mathrm{H}\right] \mathrm{QNB}$, capable of labeling all subtypes of the MR family uniformly $[35,43,52]$. By these techniques, the receptor density (Bmax, expressed as femtomoles/mg protein) and affinity (defined as the reciprocal of the dissociation constant, $\mathrm{Kd}$ ) were estimated by nonlinear regression analysis of saturation binding data.

(ii) MAO-B activity was determined radiochemically as described by Young et al., 1986 [71] using $10 \mu \mathrm{M}{ }^{14} \mathrm{C}-\mathrm{PEA}$ as the substrate. Specific MAO-B activity was determined in the presence of $100 \mu \mathrm{M}$ pargyline hydrochloride. The reaction was started by addition of ${ }^{14} \mathrm{C}$-PEA to $50 \mu \mathrm{L}$ of tissue homogenate $(0.2 \mathrm{~mL}$ final volume) and stopped by addition of $0.1 \mathrm{~mL}$ citric acid $2 \mathrm{M}$ after a 15 -min incubation at $37^{\circ} \mathrm{C}$. Deaminated reaction products were extracted into $3 \mathrm{~mL}$ toluene-ethylacetate $(1: 1, \mathrm{v} / \mathrm{v})$ and the radioactivity contained in a $1-\mathrm{mL}$ aliquot of the organic phase was counted in scintillation counter. The enzyme activity was expressed as $\mathrm{nmol} / \mathrm{mg}$ protein/h.

2.4. MRs Determination in Lymphocytes. (i) Rat lymphocytes were obtained from the spleen of controls and differently treated animals [35]. MR density and affinity in rat lymphocytes were determined as described in [52]. (ii) Human blood was collected in EDTA tubes and immediately processed to isolate lymphocytes for MR binding as previously described [72]. The lymphocytes were resuspended in the freezing solution [ $90 \%$ plasma obtained from autologous blood kept on ice $+10 \%$ dimethylsulfoxide (DMSO) ]. Immediately after, the cells were gradually frozen at $-80^{\circ} \mathrm{C}$ for $24 \mathrm{~h}$, and thereafter stored in liquid nitrogen.

Muscarinic receptors in humans were determined by binding assays using a single concentration $(\mathrm{Kd})$ of the specific tritiated ligand antagonist $\left[{ }^{3} \mathrm{H}\right] \mathrm{QNB}$ for muscarinic receptors in lymphocytes [72]. The specific binding was measured in the presence or absence of atropine. Each sample was assayed in triplicate and data were expressed as $\mathrm{fmol} / 10^{6}$ cells.

2.5. MAO-B Determination in Human Platelet. Human blood was collected in EDTA tubes and immediately processed to isolate platelets for MAO-B activity as previously described [72]. The platelet-rich plasma (PRP) was diluted with $10 \% \mathrm{DMSO}$, gradually frozen at $-80^{\circ} \mathrm{C}$ for $24 \mathrm{~h}$, and thereafter stored in liquid nitrogen.

The activity of p-MAO-B was determined radiochemically in duplicate samples as described by Coccini et al., 2002 [66] using $\left[{ }^{14} \mathrm{C}-\mathrm{PEA}\right]$ as the substrate. Specific activity was determined in the presence of pargyline hydrochloride. The enzyme activity was expressed as $\mathrm{nmol} / \mathrm{mg}$ protein $/ \mathrm{h}$.

2.6. Analytical Measurements of Total Hg Levels in Rats. Measurements of total Hg in cerebellum and blood also complemented the molecular studies to correlate neurochemical changes with the internal doses (see methods in $[43,52,73]$ ).

2.7. Statistical Analysis. Data are presented as the mean \pm standard deviation. Data analysis was performed by one-way analysis of variance (ANOVA) followed by Fisher's posthoc test using SPSS statistical software, considering probabilities $<0.05$ as significant. Statistical comparison of $\mathrm{Hg}$ concentrations between groups (Hg versus $\mathrm{Hg}+\mathrm{PCB} 153$ ) in brain and blood of dams and both offspring gender was performed using Student's $t$ Test.

\section{Results}

The present study assessed (i) firstly, the individual and joint effect of MeHg (0.5 and $1 \mathrm{mg} / \mathrm{kg} / \mathrm{day}, \mathrm{GD} 7-\mathrm{PD} 7)$ and PCB153 (20 mg/kg/day, GD10-GD16), given orally to rat dams, on the activity of cerebellar MAO-B and MRs as well as on lymphocytes MRs, both in dams and offspring 21 days postpartum; and then (ii) MAO-B activity and MRs in 7year-old children from Faroese birth cohort, wherein prenatal exposure to $\mathrm{MeHg}$ and PCB had already been demonstrated $[29,74]$.

3.1. Cerebellar MAO-B Activity. Figure 1(a) shows the effects of $1 \mathrm{mg} / \mathrm{kg} /$ day $\mathrm{MeHg}$ (GD7-PND7) and/or $20 \mathrm{mg} / \mathrm{kg} / \mathrm{day}$ PCB153 (GD10-GD16) maternal oral treatment on the cerebellar MAO-B activity at PD21 rats, evaluated both in dams and offspring (separately according to gender). 


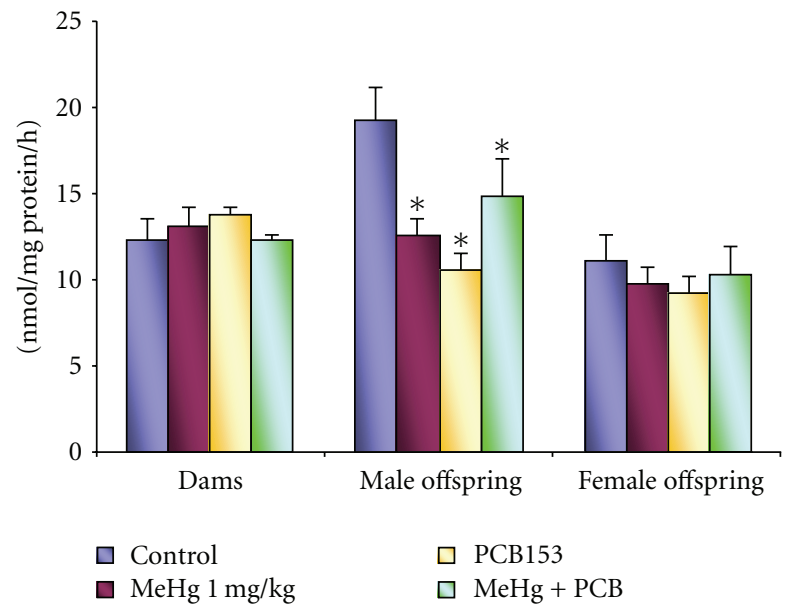

(a) Cerebellar MAO-B activity

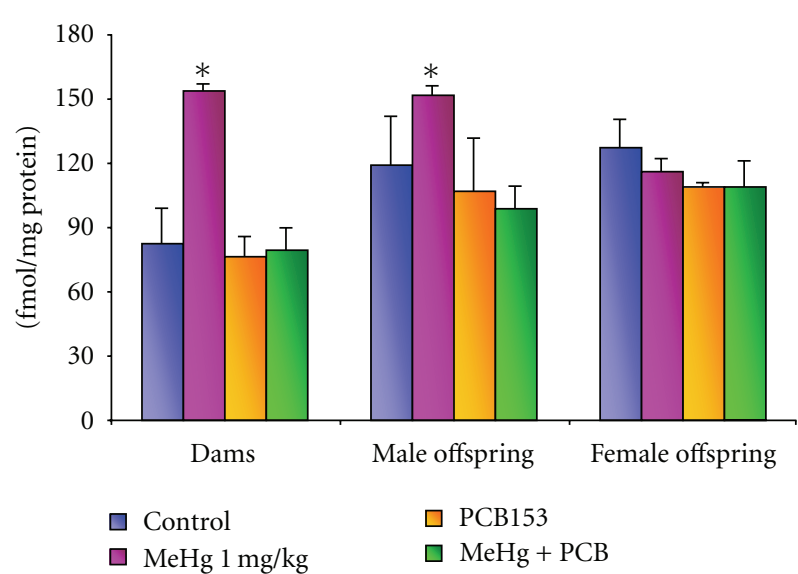

(b1) Cerebellar MRs: Bmax values

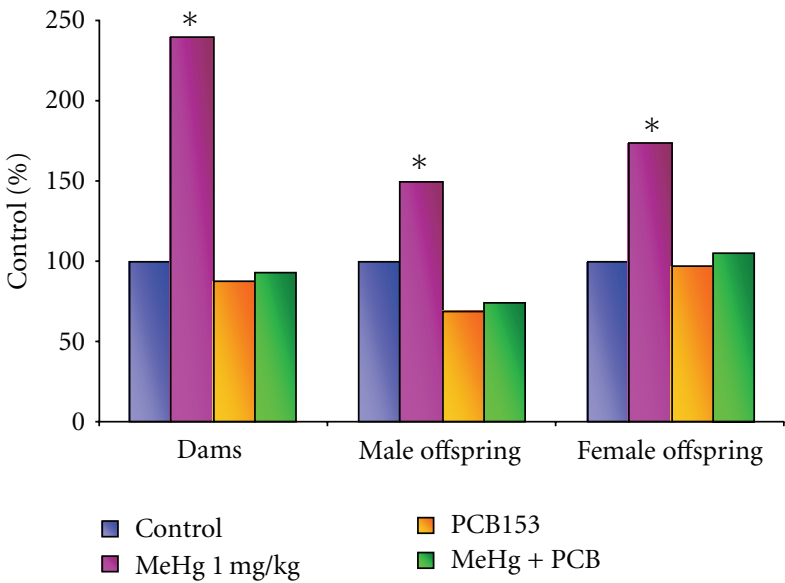

(b2) Lymphocytes MRs: Bmax values

(b)

FIGURE 1: Histograms showing cerebellar MAO-B activity (a) and MRs binding in cerebellum (b1) and lymphocytes (b2) of both dams and 21-day-old male and female rats, perinatally exposed to MeHg (1 mg/kg/day, GD7-PND7) and PCB153 (20 mg/kg/day, GD10-GD16), alone or combined. Data are the mean \pm SEM of $n=3-9$ rats/treatment group/gender. $*$ Significantly different from control group, $P<0.05$.

The doses, timing of MeHg and PCB153 administrations, and the time-point (PD21) to determine the neurochemical endpoints were selected from previous experimental data demonstrating changes in rat cerebral MRs density, following the same regimen of perinatal exposure [42]. Furthermore, this treatment protocol neither produced any noxious effect on pregnancy, litter size at birth and ratio between male and female pups, maternal or neonatal body weight increase, nor resulted in any gross abnormality to the pups (data not shown).

In male rat cerebellum, in which the control levels of MAO-B activity (nmol/mg protein/h) were $19.26 \pm 2.05$, all diverse exposures caused significant changes in the enzyme activity (Figure 1(a)). Particularly, $\mathrm{MeHg}$ decreased MAOB activity by $35 \%, \mathrm{PCB} 153$ by $45 \%$, and the combined treatment by $25 \%$. On the contrary, in female pups, this neurochemical endpoint was not affected by any treatment (Figure 1(a)), neither was in dams.
Noticeably, no effects on MAO-B activity were observed using the lower $\mathrm{MeHg}$ dose $(0.5 \mathrm{mg} / \mathrm{kg} /$ day from GD7 to PND7) in both male and female offspring (data not presented).

The radiochemical method, employed in the present study to determine MAO-B activity, did not allow the detection of this enzyme in rat platelets.

3.2. Cerebellar MRs Density (Bmax). In accordance to previous investigations [75], all determinations were done at the end of the lactational period (PND21), a time at which the total MR binding sites reach adult levels in rats.

Exposure to the higher dose of $\mathrm{MeHg}(1 \mathrm{mg} / \mathrm{kg} /$ day $)$ significantly enhanced cerebellar MRs density in dams (87\%), and, in the offspring, Bmax increase was observed in the male pups only (27\%) (Figure 1(b1)). Differently from the response to $\mathrm{MeHg}$, PCB153 did not modify cerebellar MRs density both in adult and offspring. After the concomitant 
TABLE 1: Total Hg levels in blood and brain of rats perinatally treated with $1 \mathrm{mg} \mathrm{MeHg} / \mathrm{kg}$ bw/day (GD7-PD7) and/or 20 mg PCB153/kg bw/day (GD10-GD16), alone and in combination.

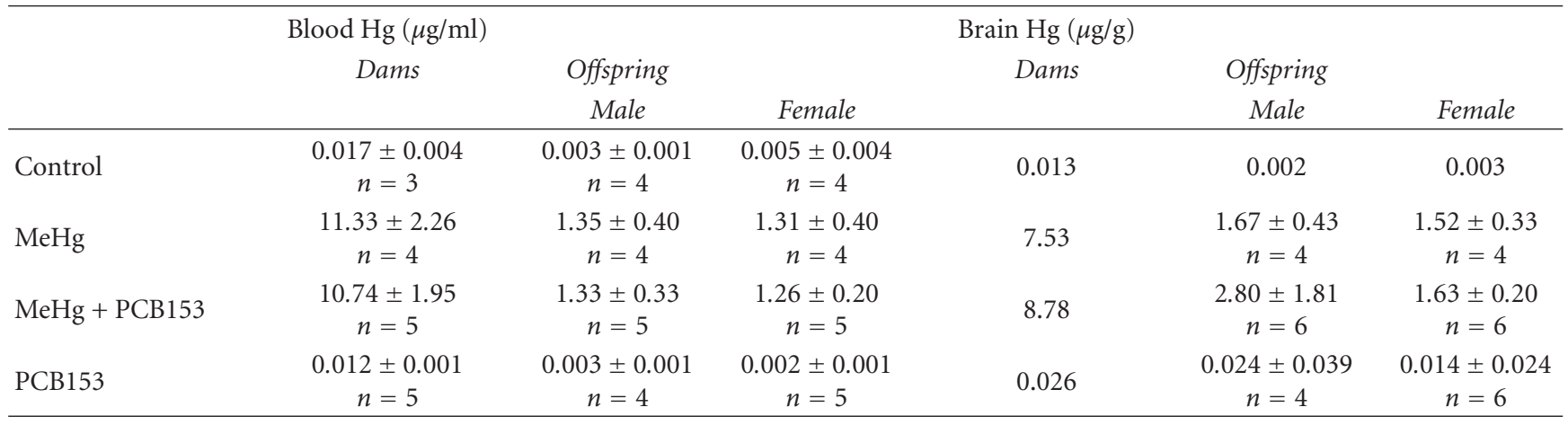

Data are the mean \pm S.D.

exposure to $\mathrm{MeHg}(1 \mathrm{mg} / \mathrm{kg} /$ day $)$ and PCB153, the MRs density was similar to that detected after the administration of PCB153 alone(Figure 1(b1)).

Noticeably, the lower dose of $\mathrm{MeHg}(0.5 \mathrm{mg} / \mathrm{kg} /$ day $)$ either alone or in combination with PCB153 did not cause any change in MR density both in the mother and offspring cerebella (data not shown).

Cerebellar control Kd values were $0.085 \pm 0.02,0.078 \pm$ $0.01,0.080 \pm 0.01 \mathrm{nM}$ in dams, male, and female offspring, respectively. $\mathrm{MeHg}$ and $\mathrm{PCB} 153$, alone and in combination, did not affect the dissociation constant values (Kd) measured both in dams and offspring, thus suggesting that the affinity of the ligand $\left[{ }^{3} \mathrm{H}\right] \mathrm{QNB}$ for its receptor was not modified by these compounds.

3.3. Lymphocytes MRs: Animal Data. Exposure to $1 \mathrm{mg}$ $\mathrm{MeHg} / \mathrm{kg} /$ day during pregnancy and lactation (from GD7 to PND7) significantly enhanced lymphocyte MR density in both dams and 21 day-old rats, with a more pronounced effect in the mothers (Bmax increase of 139\%) than in the male offspring $(+49 \%)$ and female offspring $(+73 \%)$ as compared with their respective controls $(33 \pm 4,41 \pm 8$, and $37 \pm 4 \mathrm{fmol} /$ million cells, Figure 1(b2)), in accordance with the higher $\mathrm{Hg}$ levels detected in the adult blood (11.3 \pm $2.26 \mathrm{mg} / \mathrm{mL})$ than in pups $(1.35 \pm 0.4 \mathrm{mg} / \mathrm{L}$ in both genders, Table 1), and in absence of any change in their Kd values (control Kd values were $30 \pm 10 \mathrm{nM}$ ).

Again, when the lower dose of $\mathrm{MeHg}(0.5 \mathrm{mg} / \mathrm{kg} /$ day $)$ was administered to dams, the density of MRs of all groups did not significantly differ from that of their control groups on day 21 postpartum. This dose of $\mathrm{MeHg}$ was also devoid of any effect on the Kd values (data not shown).

3.4. Brain and Blood $\mathrm{Hg}$ Levels in Rats. $\mathrm{Hg}$ levels were measured in whole brains and blood of both dams and 21day-old pups (separate accordingly to gender) treated with $1 \mathrm{mg} \mathrm{MeHg} / \mathrm{kg} / \mathrm{day}$. The $\mathrm{Hg}$ concentrations (Table 1) in the brain were about five-fold higher in the mother than in the offspring and resulted to be not affected by the coexposure to PCB153.
Regarding the $\mathrm{Hg}$ retention in blood, the levels in the dams were about 10 -fold higher than those found in both male and female offspring (Table 1).

3.5. Neurochemical Markers in Humans: Lymphocytes MRs and $p-M A O-B$. The levels of the lymphocytes MR binding $(n=139)$ and p-MAO-B activity $(n=137)$ measured in the blood of both female and male Faroese children are shown in the Figures 2(a) and 2(b). Figure 2(b) shows the single values of the MR binding in boys $(n=73)$ and girls $(n=66)$, respectively. The MR binding was similar in boys and girls and ranged from 0.1 to $36.78 \mathrm{fmol} /$ million cells in boys and from 0.1 to $35.91 \mathrm{fmol} / \mathrm{million}$ cells in girls. Figure 2(a) illustrates the individual values of the MAO-B activity in both male $(n=70)$ and female $(n=67)$ children, respectively. Even for this neurochemical endpoint, the data were similar in both genders (ranges: 0.95-14.57 and 1.57$14.95 \mathrm{nmol} / \mathrm{mg}$ protein/hr for boys and girls, resp.).

No correlation (by regression analysis) was found between the two neurochemical biomarkers and neurotoxicant concentrations in blood (pre- and postnatally) [29].

\section{Discussion}

The present study demonstrates in laboratory animals that developmental exposure to $\mathrm{MeHg}(1 \mathrm{mg} / \mathrm{kg} / \mathrm{day}$, GD7PND7) and PCB153 (20 mg/kg/day, GD10-GD16), alone and in mixture, affects selected endpoints of cholinergic and monoaminergic transmission, namely, cerebellar MAO-B activity and cerebellar and lymphocyte MRs, both in dams and weaning rats, 3 weeks after cessation of maternal dosing.

In the CNS, MAO-B activity was significantly decreased (25-45\%) by all treatment types in the cerebellum of male pups only. The combined exposure to $\mathrm{MeHg}$ and PCB153 did not exacerbate the neurochemical effects of the individual compounds.

MRs density was significantly affected by $\mathrm{MeHg}$ alone both in dams and male offspring cerebella (Bmax enhancement of $87 \%$ and $27 \%$, resp.), while, in the coexposed group, no MRs changes were observed. 

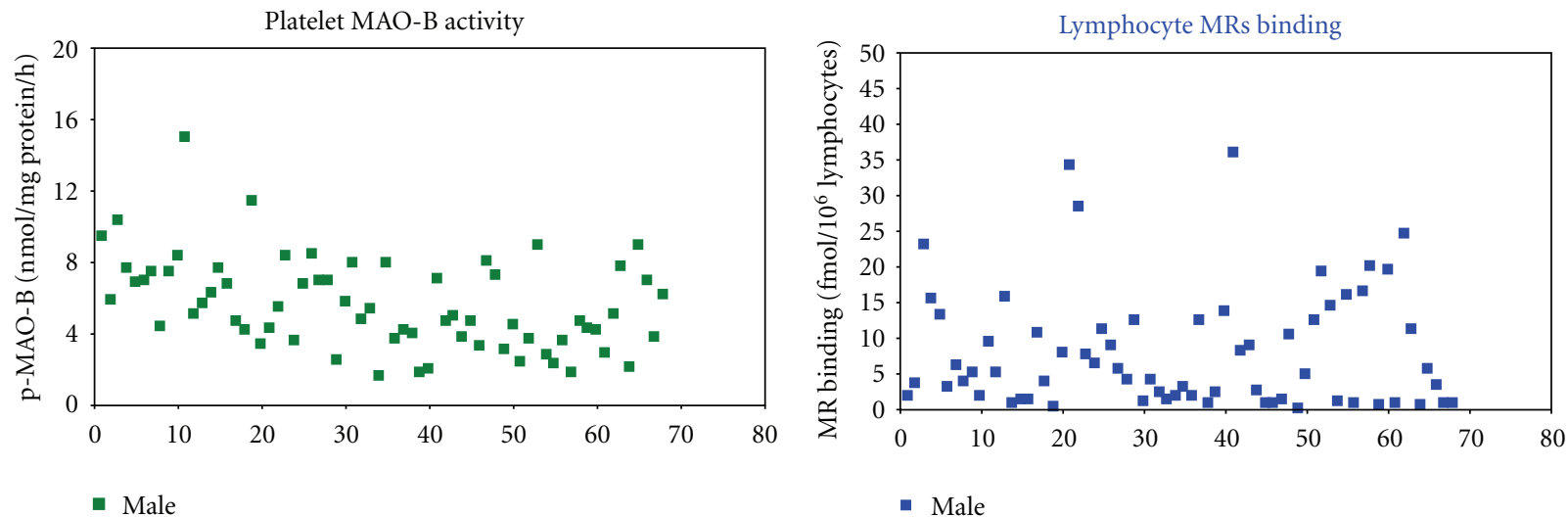

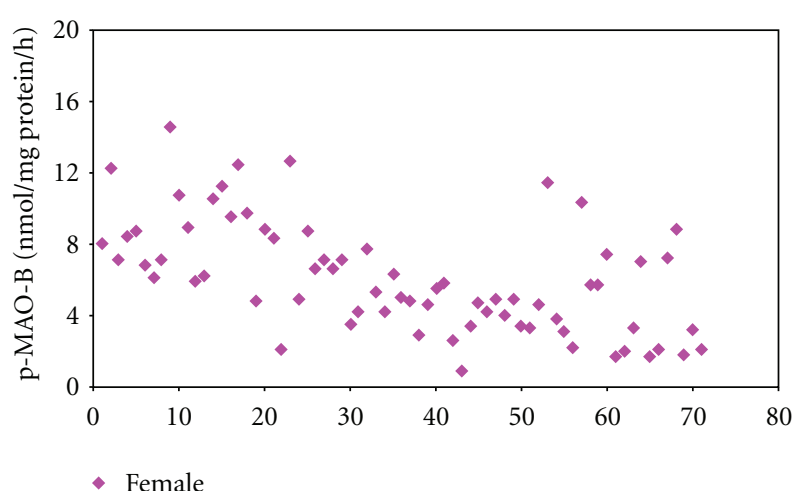

(a)

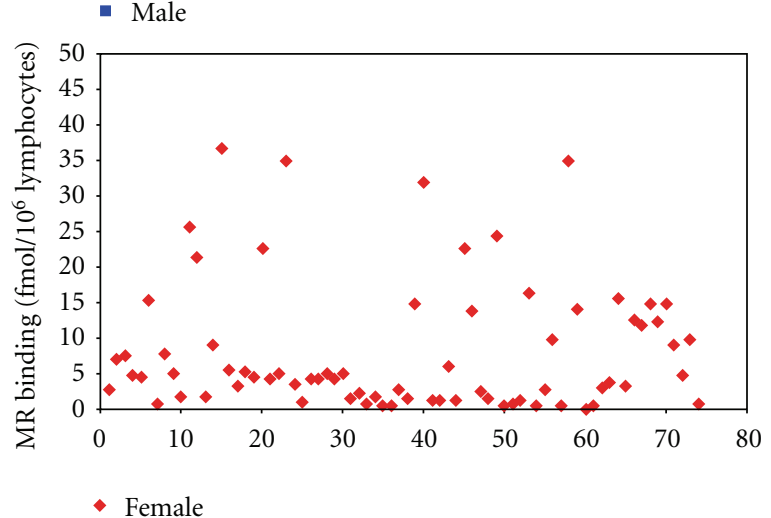

(b)

FIGURE 2: Levels of (a) p-MAO-B activity $(n=137)$ and (b) l-MR binding measured in the blood of both female and male Faroese children. (a) illustrates the individual values of the MAO-B activity in 70 boys (mean $\pm \mathrm{SD}=6.08 \pm 3.12 \mathrm{nmol} / \mathrm{mg}$ protein/h, range: $0.95-14.57$ ) and 67 girls (mean $\pm \mathrm{SD}=5.56 \pm 2.55 \mathrm{nmol} / \mathrm{mg}$ protein/h, range: $1.57-14.95$ ), respectively. (b) shows the single values of the MR binding in 73 boys (mean $\pm \mathrm{SD}=8.05 \pm 9.13 \mathrm{fmol} / 10^{6}$ cells, range: $0.1-36.78$ ) and 66 girls (mean $\pm \mathrm{SD}=8.09 \pm 8.31 \mathrm{fmol} / 10^{6}$ cells, range: $0.1-35.91$ ), respectively.

MRs measured in peripheral lymphocytes also displayed alterations similar to those occurring in the cerebellum, in that $\mathrm{MeHg}$ alone significantly enhanced MRs density both in dams and offspring, (Bmax increase of 139\%, 49\%, and 73\% for dams, males, and females, resp.), and, when in combination with PCB153, the latter compound masked the $\mathrm{MeHg}$ effects.

In another set of experiments, testing the lower $\mathrm{MeHg}$ dose $(0.5 \mathrm{mg} / \mathrm{kg} /$ day, GD7-PND21), no effects were detected for all the chosen cholinergic and monoaminergic endpoints.

Altogether the present results, obtained both in neural tissue and in peripheral cells, are in agreement with a large body of previous experimental evidence strongly supporting the notion that MR binding is modulated in a similar manner in lymphocytes and cerebral tissues. Supporting examples of this parallel modulation come from cholinergic agonist and antagonist drugs [50] as well as by environmental chemicals, such as MeHg [35] and organophosphorous insecticides [51]. Moreover, the MRs were shown to be similarly modulated in rat brain and in lymphocytes following repeated perinatal MeHg exposure [52].

Again, the present investigation demonstrates that the effects measured in lymphocytes MRs of animals coexposed to $\mathrm{MeHg}$ and $\mathrm{PCB} 153$ mirror the changes observed in cerebellum, in which the chemical mixture produced no detectable MR alterations.

Based on (i) the results obtained from this laboratory animal study (above reported), (ii) the need to identify early biomarkers of effects for delay neurological outcomes due to environmental neurotoxicants exposure, and (iii) the opportunity to measure these biochemical parameters in easily accessible non-neural tissues, we are prompted to evaluate these peripheral surrogate markers in a specific human casistic.

The human study, performed in a cohort of 7-year-old children with widely different degrees of $\mathrm{MeHg}$ exposure, with a built-in control group with low-level exposure, indicates that children exhibited homogeneous distributions of the two neurotoxicity biomarkers with no changes associated with increased concentrations of mercury or coexposure with PCB congeners and with no clear association with outcomes of clinical neurobehavioral testing.

These results seem to support the notion that p-MAO$\mathrm{B}$ and 1-MRs are not adequately sensitive markers to early detect the subclinical outcomes of $\mathrm{MeHg}$ and/or PCBs at low/ moderate exposure doses. 
Contrarily, recent investigation by Stamler et al. 2006 [68] in a Canadian fish-eating population inhabiting the St. Lawrence River (Lake St. Pierre, Quebec) demonstrated a $\mathrm{MeHg}$-induced reduction in MAO-B activity, associated with blood-Hg concentrations above $3.4 \mu \mathrm{g} / \mathrm{L}$.

On the other hand, in animal studies, the used perinatal dose of $1 \mathrm{mg} \mathrm{MeHg} / \mathrm{kg} /$ day markedly affected the rat cholinergic and aminergic systems, while, contrarily, the lower dose of $0.5 \mathrm{mg} \mathrm{MeHg} / \mathrm{kg} /$ day was totally ineffective. After the former treatment, cerebral $\mathrm{Hg}$ levels in weaning rats were $1.5-2.8 \mathrm{ppm}$ and blood $\mathrm{Hg}$ levels were $1.3 \pm 0.4 \mu \mathrm{g} / \mathrm{mL}$ (in both pup genders). These latter data are clearly much higher (250 to 40 times) compared to humans blood $\mathrm{Hg}$ levels, for instance, $1300 \mathrm{ppb}$ (in rat blood at PD21) versus 27.6 and $5.27 \mathrm{ppb}$ in cord blood and 7-year-old children blood of the present cohort, respectively [29]. These observations put forward that MeHg-exposure levels may affect the alterations in neurotransmission pathways and, consequently, the changes in both central and peripheral markers. Furthermore, other confounding factors, such as genetic variables, may also be to taken into consideration for their potential impact on the background levels of these biomarkers [76-79].

Moreover, since the precise time point at which these peripheral biomarkers become predictive of neuropsychological outcomes (noticeable later in life) has not been yet clarified, this should be investigated correlating these parameters (neurochemical and neuropsychological) in an early (e.g., cord blood) and late time point manner within the same subject. In this way, one could try to minimize the influence of the blood cell turnover on the levels of these cellcoupled surrogate markers, in that, because of this mechanism, the response to a moderate environmental toxicant exposure may not reflect the possible effect at vulnerable time windows (e.g., in utero period) that may cause permanent changes in neuropsychological outcomes.

Nevertheless, a great body of epidemiological evidence indicated the suitability of these biomarkers when employed as peripheral indicators of abnormal behaviour/personality or changes in response to a diagnosed pathological conditions [80-82], and drug dependence [66, 83-85].

Therefore, even though all these above-reported findings and the available bulk of literature seem to be sometimes and somewhere controversial, integrated approaches combining biochemical markers in combination with neurophysiological and behavioral assays could represent a valuable methodological approach by which human neurotoxicity assessment may become more focused.

\section{Conflict of Interests}

The authors declare that there is no conflict of interests.

\section{Acknowledgments}

The present study was supported by the EU Grants ANEMONE (Quality of Life and Management of Living Re-sources Programme QLK4-CT-2001-00186) and the Italian Ministry of Health. The authors wish to thank Mr. Davide Acerbi for his excellent technical assistance.

\section{References}

[1] D. C. Rice and S. Barone Jr., "Critical periods of vulnerability for the developing nervous system: evidence from humans and animal models," Environmental Health Perspectives, vol. 108, no. 3, pp. 511-531, 2000.

[2] L. G. Costa, M. Aschner, A. Vitalone, T. Syversen, and O. P. Soldin, "Developmental neuropathology of environmental agents," Annual Review of Pharmacology and Toxicology, vol. 44, pp. 87-110, 2004.

[3] M. C. Newland and E. M. Paletz, "Animal studies of methylmercury and PCBs: what do they tell us about expected effects in humans?" NeuroToxicology, vol. 21, no. 6, pp. 10031027, 2000.

[4] S. L. Schantz and J. J. Widholm, "Cognitive effects of endocrine-disrupting chemicals in animals," Environmental Health Perspectives, vol. 109, no. 12, pp. 1197-1206, 2001.

[5] R. A. Lincoln, J. P. Shine, E. J. Chesney, D. J. Vorhees, P. Grandjean, and D. B. Senna, "Fish consumption and mercury exposure among louisiana recreational anglers," Environmental Health Perspectives, vol. 119, pp. 245-251, 2011.

[6] P. Grandjean and K. T. Herz, "Methylmercury and brain development: imprecision and underestimation of developmental neurotoxicity in humans," Mount Sinai Journal of Medicine, vol. 78, pp. 107-118, 2011.

[7] L. Needham, P. Grandjean, B. Heinzow et al., "Partition of environmental chemicals between maternal and fetal blood and tissues," Environmental Science \& Technology, vol. 45, pp. 1121-1126, 2011.

[8] P. Grandjean, P. Weihe, R. F. White et al., "Cognitive deficit in 7-year-old children with prenatal exposure to methylmercury," Neurotoxicology and Teratology, vol. 19, no. 6, pp. 417428, 1997.

[9] K. Murata, P. Weihe, A. Renzoni et al., "Delayed evoked potentials in children exposed to methylmercury from seafood," Neurotoxicology and Teratology, vol. 21, no. 4, pp. 343-348, 1999.

[10] P. Grandjean and P. Landrigan, "Developmental neurotoxicity of industrial chemicals," The Lancet, vol. 368, no. 9553, pp. 2167-2178, 2006.

[11] S. Ceccatelli, E. Daré, and M. Moors, "Methylmercury-induced neurotoxicity and apoptosis," Chemico-Biological Interactions, vol. 188, no. 2, pp. 301-308, 2010.

[12] P. Grandjean, P. Weihe, V. W. Burse et al., "Neurobehavioral deficits associated with PCB in 7-year-old children prenatally exposed to seafood neurotoxicants," Neurotoxicology and Teratology, vol. 23, no. 4, pp. 305-317, 2001.

[13] P. W. Stewart, J. Reihman, E. I. Lonky, and T. J. Darvill, "Cognitive development in preschool children prenatally exposed to PCBs and MeHg," Neurotoxicology and Teratology, vol. 25, no. 1, pp. 11-22, 2003.

[14] J. L. Jacobson and S. W. Jacobson, "Intellectual impairment in children exposed to polychlorinated biphenyls in utero," The New England Journal of Medicine, vol. 335, no. 11, pp. 783789, 1996.

[15] E. Holene, I. Nafstad, J. U. Skaare, and T. Sagvolden, "Behavioural hyperactivity in rats following postnatal exposure to sub- toxic doses of polychlorinated biphenyl congeners 153 and 126," Behavioural Brain Research, vol. 94, no. 1, pp. 213224, 1998.

[16] A. Roth-Haerer, H. Lilienthal, M. Bubser et al., "Neurotransmitter concentrations and binding at dopamine receptors in rats after maternal exposure to 3,4,30,40,-tetrachlorobiphenyl: 
the role of reduced thyroid hormone concentrations," Environmental Toxicology and Pharmacology, vol. 9, no. 3, pp. 103115, 2001.

[17] S. L. Schantz, J. Moshtaghian, and D. K. Ness, "Spatial learning deficits in adult rats exposed to ortho-substituted PCB congeners during gestation and lactation," Fundamental and Applied Toxicology, vol. 26, no. 1, pp. 117-126, 1995.

[18] H. A. Tilson and P. R. S. Kodavanti, "Neurochemical effects of polychlorinated biphenyls: an overview and identification of research needs," NeuroToxicology, vol. 18, no. 3, pp. 727-744, 1997.

[19] C. S. Roegge, V. C. Wang, B. E. Powers et al., "Motor impairment in rats exposed to PCBs and methylmercury during early development," Toxicological Sciences, vol. 77, no. 2, pp. 315324, 2004.

[20] D. A. Cory-Slechta, "Studying toxicants as single chemicals: does this strategy adequately identify neurotoxic risk?" NeuroToxicology, vol. 26, no. 4, pp. 491-510, 2005.

[21] L. Manzo, F. Artigas, E. Martine et al., "Biochemical markers of neurotoxicity. A review of mechanistic studies and applications," Human \& Experimental Toxicology, vol. 15, supplement 1, pp. S20-S35, 1996.

[22] L. Manzo, A. F. Castoldi, T. Coccini, A. D. Rossi, P. L. Nicotera, and L. G. Costa, "Mechanisms of neurotoxicity: applications to human biomonitoring," Toxicology Letters, vol. 77, pp. 6372, 1995.

[23] E. K. Silbergeld and D. L. Davis, "Role of biomarkers in identifying and understanding environmentally induced disease," Clinical Chemistry, vol. 40, no. 7, pp. 1363-1367, 1994.

[24] A. F. Castoldi, T. Coccini, A. Rossi et al., "Biomarkers in environmental medicine: alterations of cell signalling as early indicators of neurotoxicity," Functional Neurology, vol. 9, no. 2, pp. 101-109, 1994.

[25] A. F. Castoldi, S. M. Candura, P. Costa, L. Manzo, and L. G. Costa, "Interaction of mercury compounds with muscarinic receptor subtypes in the rat brain," NeuroToxicology, vol. 17, no. 3-4, pp. 735-742, 1996.

[26] L. G. Costa, "Biomarker research in neurotoxicology: the role of mechanistic studies to bridge the gap between the laboratory and epidemiological investigations," Environmental Health Perspectives, vol. 104, no. 1, pp. 55-67, 1996.

[27] L. Manzo, A. F. Castoldi, T. Coccini, and L. D. Prockop, "Assessing effects of neurotoxic pollutants by biochemical markers," Environmental Research Section A, vol. 85, no. 1, pp. 3136, 2001.

[28] A. F. Castoldi, F. Blandini, G. Randine, A. Samuele, L. Manzo, and T. Coccini, "Brain monoaminergic neurotransmission parameters in weanling rats after perinatal exposure to methylmercury and 2,2',4,4',5,5' -hexachlorobiphenyl (PCB153)," Brain Research, vol. 1112, no. 1, pp. 91-98, 2006.

[29] T. Coccini, L. Manzo, F. Debes, U. Steuerwald, P. Weihe, and P. Grandjean, "No changes in lymphocyte muscarinic receptors and platelet monoamine oxidase-B examined as surrogate central nervous system biomarkers in a Faroese children cohort prenatally exposed to methylmercury and polychlorinated biphenyls," Biomarkers, vol. 14, no. 2, pp. 67-76, 2009.

[30] C. F. Hohmann and J. Berger-Sweeney, "Cholinergic regulation of cortical development and plasticity: new twists to an old story," Perspectives on Developmental Neurobiology, vol. 5, no. 4, pp. 401-425, 1998.

[31] Y. Yuan and W. D. Atchison, "Disruption by methylmercury of membrane excitability and synaptic transmission of CA1 neurons in hippocampal slices of the rat," Toxicology and Applied Pharmacology, vol. 120, no. 2, pp. 203-215, 1993.

[32] T. L. Limke, S. R. Heidemann, and W. D. Atchison, "Disruption of intraneuronal divalent cation regulation by methylmercury: are specific targets involved in altered neuronal development and cytotoxicity in methylmercury poisoning?" NeuroToxicology, vol. 25, no. 5, pp. 741-760, 2004.

[33] N. Basu, C. J. Stamler, K. M. Loua, and H. M. Chan, "An interspecies comparison of mercury inhibition on muscarinic acetylcholine receptor binding in the cerebral cortex and cerebellum," Toxicology and Applied Pharmacology, vol. 205, no. 1, pp. 71-76, 2005.

[34] A. F. Castoldi, T. Coccini, S. Ceccatelli, and L. Manzo, "Neurotoxicity and molecular effects of methylmercury," Brain Research Bulletin, vol. 55, no. 2, pp. 197-203, 2001.

[35] T. Coccini, G. Randine, S. M. Candura, R. E. Nappi, L. D. Prockop, and L. Manzo, "Low-level exposure to methylmercury modifies muscarinic cholinergic receptor binding characteristics in rat brain and lymphocytes: physiologic implications and new opportunities in biologic monitoring," Environmental Health Perspectives, vol. 108, no. 1, pp. 29-33, 2000.

[36] M. E. Eldefrawi, N. A. Mansour, and A. T. Eldefrawi, "Interactions of acetylcholine receptors with organic mercury compounds," Advances in Experimental Medicine and Biology, vol. 84, pp. 449-463, 1977.

[37] P. D. Hrdina, D. A. V. Peters, and R. L. Singhal, "Effects of chronic exposure to cadmium, lead and mercury on brain biogenic amines in the rat," Research Communications in Chemical Pathology \& Pharmacology, vol. 15, no. 3, pp. 483-493, 1976.

[38] H. Kobayashi, A. Yuyama, N. Matsusaka, K. Takeno, and I. Yanagiya, "Effects of methylmercury chloride on various cholinergic parameters in vitro," Journal of Toxicological Sciences, vol. 4, no. 4, pp. 351-362, 1979.

[39] Y. Tsuzuki, "Effect of chronic methylmercury exposure on activities of neurotransmitter enzymes in rat cerebellum," Toxicology and Applied Pharmacology, vol. 60, no. 2, pp. 379-381, 1981.

[40] R. Von Burg, F. K. Northington, and A. Shamoo, "Methylmercury inhibition of rat brain muscarinic receptors," Toxicology and Applied Pharmacology, vol. 53, no. 2, pp. 285-292, 1980.

[41] P. Eriksson, U. Lundkvist, and A. Frederiksson, "Neonatal exposure to 3,30,40-tetrachlorobiphenyl: changes in spontaneous behaviour and cholinergic muscarinic receptors in the adult mouse," Toxicology, vol. 69, no. 1, pp. 27-34, 1991.

[42] T. Coccini, G. Randine, A. F. Castoldi et al., "Effects of developmental co-exposure to methylmercury and 2,29,4,49,5,59hexachlorobiphenyl (PCB153) on cholinergic muscarinic receptors in rat brain," NeuroToxicology, vol. 27, no. 4, pp. 468477, 2006.

[43] T. Coccini, E. Roda, A. F. Castoldi et al., "Perinatal co-exposure to methylmercury and PCB153 or PCB126 in rats alters the cerebral cholinergic muscarinic receptors at weaning and puberty," Toxicology, vol. 238, no. 1, pp. 34-48, 2007.

[44] K. Masuyama, K. Uno, R. Minoda, M. Eura, Y. Samejima, and T. Ishikawa, "Muscarinic acetylcholine receptors on human lymphocytes in patients with Meniere's disease," Acta Oto-Laryngologica, vol. 116, no. 3, pp. 369-373, 1996.

[45] C. C. Felder, F. P. Bymaster, J. Ward, and N. DeLapp, "Therapeutic opportunities for muscarinic receptors in the central nervous system," Journal of Medicinal Chemistry, vol. 43, no. 23, pp. 4333-4353, 2000. 
[46] R. M. Eglen, A. Choppin, and N. Watson, "Therapeutic opportunities from muscarinic receptor research," Trends in Pharmacological Sciences, vol. 22, no. 8, pp. 409-414, 2001.

[47] J. Wess, "Muscarinic acetylcholine receptor knockout mice: novel phenotypes and clinical implications," Annual Review of Pharmacology and Toxicology, vol. 44, pp. 423-450, 2004.

[48] R. M. Eglen, "Muscarinic receptor subtype pharmacology and physiology," Progress in Medicinal Chemistry, vol. 43, pp. 105136, 2005.

[49] K. Kawashima and T. Fujii, "The lymphocytic cholinergic system and its contribution to the regulation of immune activity," Life Sciences, vol. 74, no. 6, pp. 675-696, 2003.

[50] L. G. Costa, G. Kaylor, and S. D. Murphy, "In vitro and in vivo modulation of cholinergic muscarinic receptors in rat lymphocytes and brain by cholinergic agents," International Journal of Immunopharmacology, vol. 12, no. 1, pp. 67-75, 1990.

[51] B. B. Fitzgerald and L. G. Costa, "Modulation of muscarinic receptors and acetylcholinesterase activity in lymphocytes and in brain areas following repeated organophosphate exposure in rats," Fundamental and Applied Toxicology, vol. 20, no. 2, pp. 210-216, 1993.

[52] T. Coccini, G. Randine, A. F. Castoldi, D. Acerbi, and L. Manzo, "Methylmercury interaction with lymphocyte cholinergic muscarinic receptors in developing rats," Environmental Research, vol. 103, no. 2, pp. 229-237, 2007.

[53] A. D. Rossi, E. Ahlbom, S. O. Ogren, P. Nicotera, and S. Beccatelli, "Prenatal exposure to methylmercury alters locomotor activity of male but not female rats," Experimental Brain Research, vol. 117, no. 3, pp. 428-436, 1997.

[54] L. Gimenez-Llort, E. Ahlbom, E. Daré, M. Vahter, S. O. Ogren, and S. Ceccatelli, "Prenatal exposure to methylmercury changes dopamine-modulated motor activity during early ontogeny: age and gender-dependent effects," Environmental Toxicology and Pharmacology, vol. 9, no. 3, pp. 61-70, 2001.

[55] H. Komulainen and J. Tuomisto, "Interference of methyl mercury with monoamine uptake and release in rat brain synaptosomes," Acta Pharmacologica et Toxicologica, vol. 48, no. 3, pp. 214-222, 1981.

[56] D. J. Minnema, G. P. Cooper, and R. D. Greenland, "Effects of methylmercury on neurotransmitter release from rat brain synaptosomes," Toxicology and Applied Pharmacology, vol. 99, no. 3, pp. 510-521, 1989.

[57] W. Shain, B. Bush, and R. F. Seegal, "Neurotoxicity of polychlorinated biphenyls: structure-activity relationship of individual congeners," Toxicology and Applied Pharmacology, vol. 111 , no. 1, pp. 33-42, 1991.

[58] J. C. Bemis and R. F. Seegal, "Polychlorinated biphenyls and methylmercury act synergistically to reduce rat brain dopamine content in vitro," Environmental Health Perspectives, vol. 107, no. 11, pp. 879-885, 1999.

[59] M. A. Chishti, J. P. Fisher, and R. F. Seegal, "Aroclors 1254 and 1260 reduce dopamine concentrations in rat striatal slices," NeuroToxicology, vol. 17, no. 3-4, pp. 653-660, 1996.

[60] T. Coccini, E. Roda, A. F. Castoldi et al., "Developmental exposure to methylmercury and 2,2',4,4',5,5'-hexachlorobiphenyl (PCB153) affects cerebral dopamine D1-likeand D2-like receptors of weanling and pubertal rats," Archives of Toxicology, vol. 85, no. 10, pp. 1281-1294, 2011.

[61] S. K. Chakrabarti, K. M. Loua, C. Bai, H. Durham, and J.C. Panisset, "Modulation of monoamine oxidase activity in different brain regions and platelets following exposure of rats to methylmercury," Neurotoxicology and Teratology, vol. 20, no. 2, pp. 161-168, 1998.
[62] P. Beyrouty, C. J. Stamler, J. N. Liu, S. Kubow, and H. M. Chan, "Effects of prenatal methylmercury exposure on brain monoamine oxidase activity and neurobehaviour of rats," Neurotoxicology and Teratology, vol. 28, no. 2, pp. 251-259, 2006.

[63] D. R. Vincent, W. S. Bradshaw, G. M. Booth, R. E. Seegmiller, and S. D. Allen, "Effect of PCB and DES on rat monoamine oxidase, acetylcholinesterase, testosterone, and estradiol ontogeny," Bulletin of Environmental Contamination and Toxicology, vol. 48, no. 6, pp. 884-893, 1992.

[64] K. Chen, H. F. Wu, and J. C. Shih, "The deduced amino acid sequences of human platelet and frontal cortex monoamine oxidase B are identical," Journal of Neurochemistry, vol. 61, no. 1, pp. 187-190, 1993.

[65] C. H. Donnelly and D. L. Murphy, "Substrate and inhibitor related characteristics of human platelet monoamine oxidase," Biochemical Pharmacology, vol. 26, no. 9, pp. 853-858, 1977.

[66] T. Coccini, A. F. Castoldi, C. Gandini et al., "Platelet monoamine oxidase B activity as a state marker for alcolism: trend over time during withdrawal and influence of smoking and gender," Alcohol and Alcoholism, vol. 37, no. 6, pp. 566-572, 2002.

[67] C. J. Fowler and K. F. Tipton, "Deamination of 5-hydroxytryptamine by both forms of monoamine oxidase in the rat brain," Journal of Neurochemistry, vol. 38, no. 3, pp. 733-736, 1982.

[68] C. J. Stamler, N. Abdelouahab, C. Vanier, D. Mergler, and H. M. Chan, "Relationship between platelet monoamine oxidase$\mathrm{B}$ (MAO-B) activity and mercury exposure in fish consumers from the Lake St. Pierre region of Que., Canada," NeuroToxicology, vol. 27, no. 3, pp. 429-436, 2006.

[69] J. B. Whitfield, D. Pang, K. K. Bucholz et al., "Monoamine oxidase: associations with alcohol dependence, smoking and other measures of psychopathology," Psychological Medicine, vol. 30, no. 2, pp. 443-454, 2000.

[70] R. T. Wyatt, D. L. Murphy, R. Belmaker, S. Cohen, C. H. Donnelly, and W. Pollin, "Reduced monoamine oxidase activity in platelets: a possible genetic marker for vulnerability to schizophrenia," Science, vol. 179, no. 4076, pp. 916-918, 1973.

[71] W. F. Young, E. R. Laws, F. W. Sharbrough, and R. M. Weinshilboum, "Human monoamine oxidase. Lack of brain and platelet correlation," Archives of General Psychiatry, vol. 43, no. 6, pp. 604-609, 1986.

[72] T. Coccini, G. Randine, A. F. Castoldi, L. Balloni, P. Baiardi, and L. Manzo, "Lymphocyte muscarinic receptors and platelet monoamine oxidase-B as biomarkers of CNS function: effects of age and gender in healthy humans," Environmental Toxicology and Pharmacology, vol. 19, no. 3, pp. 715-720, 2005.

[73] P. Grandjean, E. Budtz-Jørgensen, P. J. Jørgensen, and P. Weihe, "Umbilical cord mercury concentration as biomarker of prenatal exposure to methylmercury," Environmental Health Perspectives, vol. 113, no. 7, pp. 905-908, 2005.

[74] U. Steuerwald, P. Weihe, P. J. Jørgensen et al., "Maternal seafood diet, methylmercury exposure, and neonatal neurologic function," Journal of Pediatrics, vol. 136, no. 5, pp. 599-605, 2000.

[75] I. Aubert, D. Cécyre, S. Gauthier, and R. Quirion, “Comparative ontogenic profile of cholinergic markers, including nicotinic and muscarinic receptors, in the rat brain," Journal of Comparative Neurology, vol. 369, no. 1, pp. 31-55, 1996.

[76] D. M. Dick, F. Aliev, J. Kramer et al., "Association of CHRM2 with IQ: converging evidence for a gene influencing intelligence," Behavior Genetics, vol. 37, no. 2, pp. 265-272, 2007. 
[77] M. F. Gosso, M. van Belzen, E. J. C. de Geus et al., "Association between the CHRM2 gene and intelligence in a sample of 304 Dutch families," Genes, Brain and Behavior, vol. 5, no. 8, pp. 577-584, 2006.

[78] L. Oreland and C. Fowler, "Brain and platelet monoamine oxidase activities in relation to central monoaminergic activity in mice and man," in Monoamine Oxidase: Basic and Clinical Frontiers, K. Kamijo, E. Usdin, and T. Nagatsu, Eds., pp. 312 320, Excerpta Medica, Amsterdam, The Netherlands, 1982.

[79] L. Oreland, K. Nilsson, M. Damberg, and J. Hallman, "Monoamine oxidases-activities, genotypes and the shaping of behaviour," Journal of Neural Transmission, vol. 114, no. 6, pp. 817-822, 2007.

[80] W. Danielczyk, M. Streifler, C. Konradi, P. Riederer, and G. Moll, "Platelet MAO-B activity and the psychopathology of Parkinson's disease, senile dementia and multi-infarct dementia," Acta Psychiatrica Scandinavica, vol. 78, no. 6, pp. 730-736, 1988.

[81] R. J. Perry and J. R. Hodges, "Attention and executive deficits in Alzheimer's disease: a critical review," Brain, vol. 122, no. 3, pp. 383-404, 1999.

[82] M. Sandler, M. A. Reveley, and V. Glover, "Human platelet monoamine oxidase activity in health and disease: a review," Journal of Clinical Pathology, vol. 34, no. 3, pp. 292-302, 1981.

[83] R. M. Anthenelli, T. L. Smith, C. E. Craig, B. Tabakoff, and M. A. Schuckit, "Platelet monoamine oxidase activity levels in subgroups of alcoholics: diagnostic, temporal, and clinical correlates," Biological Psychiatry, vol. 38, no. 6, pp. 361-368, 1995.

[84] L. D. Snell, J. Glanz, and B. Tabakoff, "Relationships between effects of smoking, gender, and alcohol dependence on platelet monoamine oxidase-B: activity, affinity labeling, and protein measurements," Alcoholism, vol. 26, no. 7, pp. 1105-1113, 2002.

[85] J. L. Sullivan, J. C. Baenziger, D. L. Wagner, F. P. Rauscher, J. I. Nurnberger Jr., and J. S. Holmes, "Platelet MAO in subtypes of alcoholism," Biological Psychiatry, vol. 27, no. 8, pp. 911-922, 1990. 

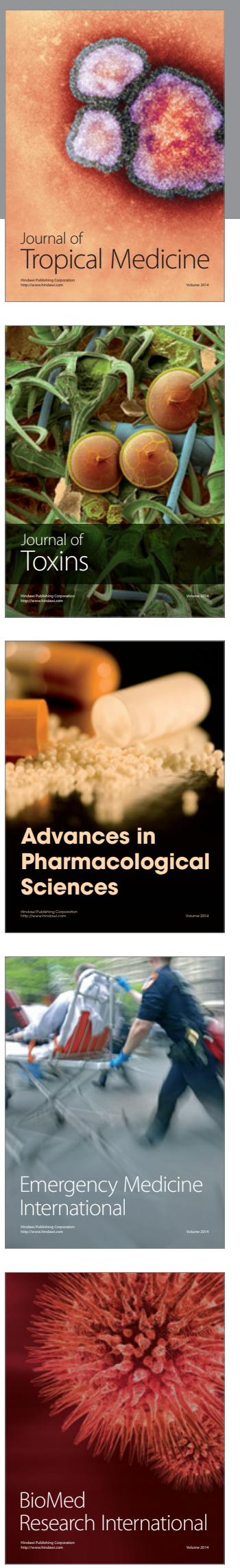
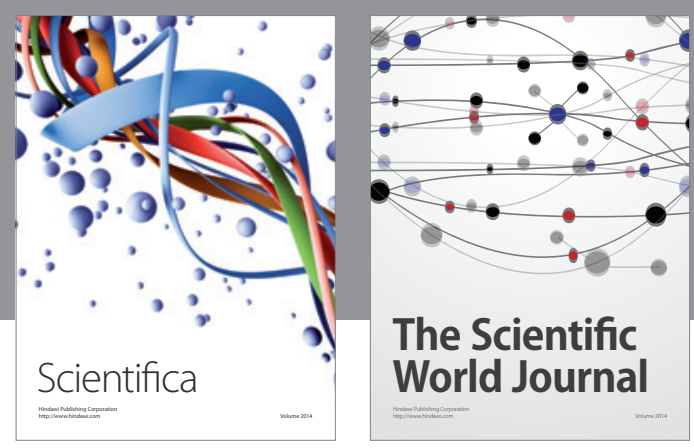

The Scientific World Journal
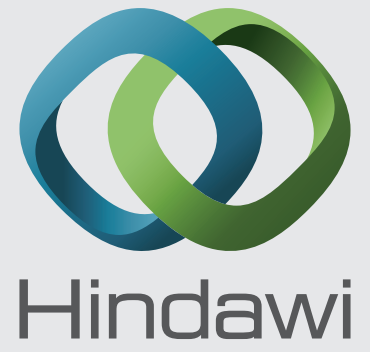

Submit your manuscripts at

http://www.hindawi.com
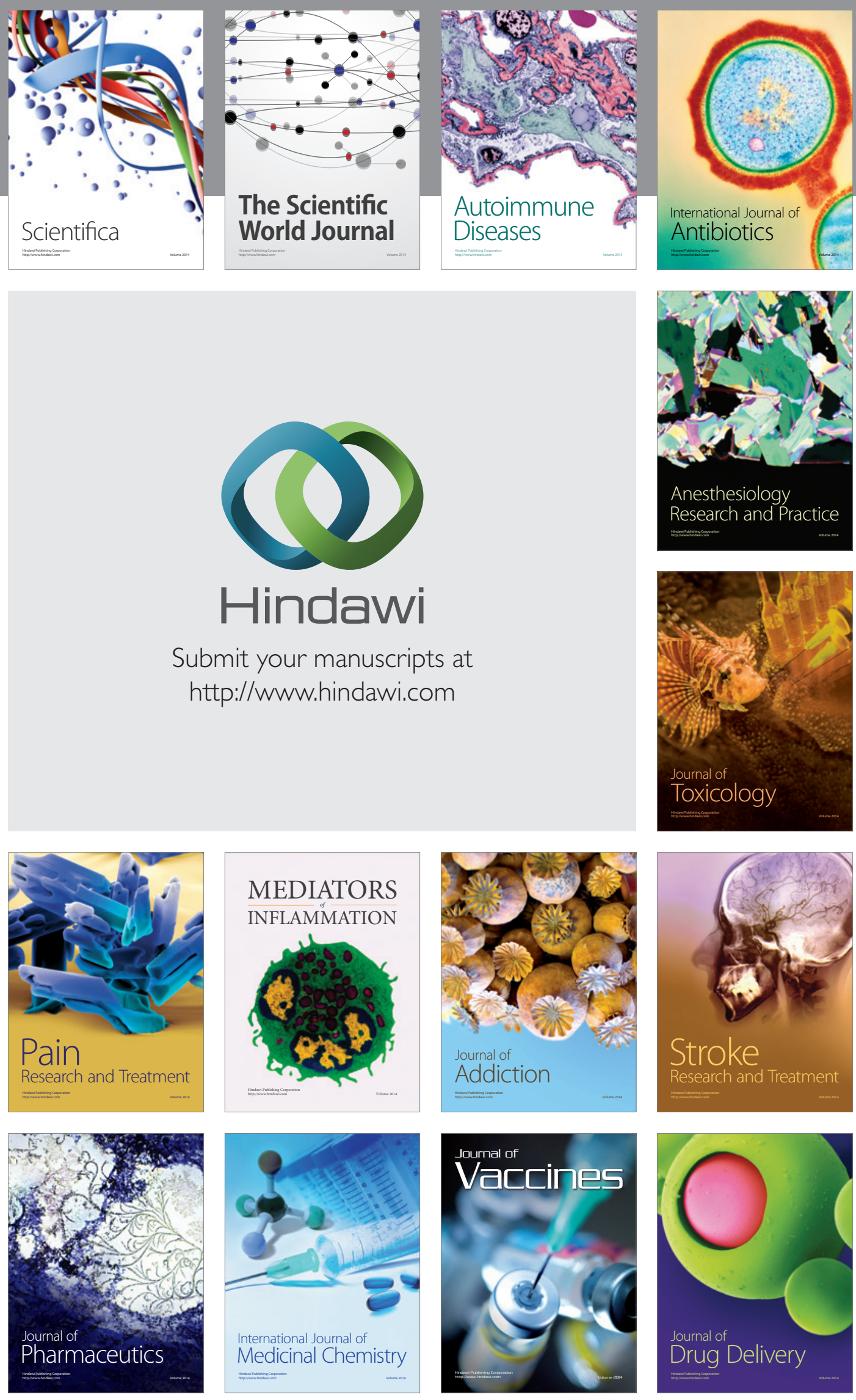